\title{
ARTICLE
}

Clinical Study

\section{Diagnostic performance of a faecal immunochemical test for patients with low-risk symptoms of colorectal cancer in primary care: an evaluation in the South West of England}

Sarah E. R. Bailey (D) ${ }^{1}$, Gary A. Abel ${ }^{1}$, Alex Atkins ${ }^{2}$, Rachel Byford ${ }^{3}$, Sarah-Jane Davies ${ }^{4}$, Joe Mays ${ }^{4}$, Timothy J. McDonald ${ }^{5}$, Jon Miller ${ }^{4}$, Catherine Neck ${ }^{6}$, John Renninson ${ }^{4}$, Paul Thomas ${ }^{7}$, Fiona M. Walter ${ }^{8}$, Sarah Warren ${ }^{6}$ and Willie Hamilton ${ }^{1}$

BACKGROUND: The faecal immunochemical test (FIT) was introduced to triage patients with low-risk symptoms of possible colorectal cancer in English primary care in 2017, underpinned by little primary care evidence.

METHODS: All healthcare providers in the South West of England (population 4 million) participated in this evaluation. 3890 patients aged $\geq 50$ years presenting in primary care with low-risk symptoms of colorectal cancer had a FIT from 01/06/2018 to $31 /$ $12 / 2018$. A threshold of $10 \mu \mathrm{g} \mathrm{Hb} / \mathrm{g}$ faeces defined a positive test.

RESULTS: Six hundred and eighteen (15.9\%) patients tested positive; 458 (74.1\%) had an urgent referral to specialist lower gastrointestinal (Gl) services within three months. Forty-three were diagnosed with colorectal cancer within 12 months. 3272 tested negative; 324 (9.9\%) had an urgent referral within three months. Eight were diagnosed with colorectal cancer within 12 months. Positive predictive value was $7.0 \%$ (95\% Cl 5.1-9.3\%). Negative predictive value was $99.8 \%$ (Cl 99.5-99.9\%). Sensitivity was $84.3 \%$ (Cl 71.4-93.0\%), specificity $85.0 \%$ (Cl 83.8-86.1\%). The area under the ROC curve was $0.92(\mathrm{Cl} 0.86-0.96)$. A threshold of $37 \mu \mathrm{g} \mathrm{Hb} / \mathrm{g}$ faeces would identify patients with an individual $3 \%$ risk of cancer.

CONCLUSIONS: FIT performs exceptionally well to triage patients with low-risk symptoms of colorectal cancer in primary care; a higher threshold may be appropriate in the wake of the COVID-19 crisis.

British Journal of Cancer (2021) 124:1231-1236; https://doi.org/10.1038/s41416-020-01221-9

\section{BACKGROUND}

There are around 1.8 million new colorectal cancer (CRC) diagnoses worldwide each year, and almost 900,000 deaths. ${ }^{1}$ Population screening is effective in reducing mortality, with a relative risk of CRC mortality varying between 0.67 and 0.88 depending upon the screening modality, frequency of screening and sex. ${ }^{2}$ However, even when screening is available, most CRCs present with symptoms. In the UK, less than $10 \%$ of CRCs are identified by screening, with the remainder identified after symptoms have developed. ${ }^{3}$ In many countries, symptomatic patients present first to primary care, where the general practitioner (GP) assesses the possibility of cancer, and investigates or refers for specialist tests if appropriate. ${ }^{4}$ The usual diagnostic test in secondary care is colonoscopy, with CT imaging or capsule endoscopy occasionally used.

Requests for urgent CRC investigation have relentlessly increased over the last decade, with a parallel increase in colonoscopies. These doubled in the UK between 2012 and 2017.5 This rise was driven in part by referral of patients whose symptom profile, while still representing possible cancer, was relatively low-risk. ${ }^{6}$ These patients, often with abdominal pain or mild anaemia, had been excluded from UK national guidance in $2005^{7}$ but transpired to have the worst survival across the different symptoms, often presenting as an emergency. ${ }^{8,9}$ In 2015, the National Institute for Health and Care Excellence (NICE) published revised guidance, NG12. ${ }^{10}$ The revised NICE recommendations were explicitly based on the risk of cancer posed by the patient's symptoms, and used only primary care evidence to estimate this risk. Patients having a risk of CRC of $3 \%$ or more are recommended for an urgent suspected cancer referral, and are usually offered colonoscopy. For risks below $3 \%$, patients were to be offered testing for occult blood in their faeces, with those testing positive to be referred urgently. This recommendation was based on a systematic review performed by NICE, finding six studies of faecal occult blood testing mostly in secondary care, totalling 9871 patients. $^{10}$ The sensitivity and specificity for colorectal cancer varied considerably across these studies, although the diagnostic performance was considered sufficient in the absence

\footnotetext{
${ }^{1}$ University of Exeter Medical School, St Luke's Campus, Magdalen Road, Exeter EX1 2LU, UK; ${ }^{2}$ Cancer Performance and Development Team, Royal Devon \& Exeter NHS Foundation Trust, Barrack Road, Exeter EX2 5DW, UK; ${ }^{3}$ Cancer Research UK, 2 Redman Place, London E20 1JQ, UK; ${ }^{4}$ Peninsula Cancer Alliance, South West Clinical Networks \& Senate, NHS England and NHS Improvement, South West House, Taunton, Somerset TA1 2PX, UK; ${ }^{5}$ The Academic Department of Blood Sciences, Exeter Clinical Laboratory, Royal Devon \& Exeter NHS Foundation Trust, Barrack Road, Exeter EX2 5DW, UK; ${ }^{6}$ NHS South, Central, and West Commissioning Support Unit, South Plaza, Marlborough Street, Bristol

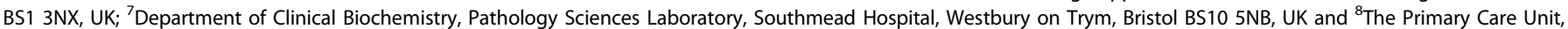
Department of Public Health and Primary Care, University of Cambridge, Cambridge CB1 8RN, UK

Correspondence: Sarah E. R. Bailey (s.e.r.bailey@exeter.ac.uk)
}

Received: 9 September 2020 Revised: 20 November 2020 Accepted: 2 December 2020

Published online: 19 January 2021 
1232

of other tests available in primary care. An economic evaluation supported this recommendation. ${ }^{10}$

The faecal immunochemical test (FIT) for haemoglobin measures the amount of haemoglobin in a faeces sample and has largely replaced faecal occult blood testing. NICE guidance issued in 2017 (DG30) recommended FIT should replace faecal occult blood testing in primary care patients with low-risk symptoms of CRC. ${ }^{11}$ The systematic review underpinning that recommendation found nine studies: ${ }^{12}$ in only one was the FIT performed in primary care, though even in that study all patients had already been selected for urgent referral for possible CRC. ${ }^{13}$ Thus all the evidence underpinning the use of FITs in primary care in DG30 was from the high-risk referred population; this brings a substantial risk of spectrum bias. ${ }^{14}$

This study evaluated a FIT used by general practitioners to triage patients with low-risk symptoms of possible CRC in the South West of England, and estimated the diagnostic performance of FITs in this population.

\section{METHODS}

This joint South West Cancer Alliances transformation project provided a quantitative FIT service to primary care practices across the South West of England (population 4 million) from June 2018. This area includes 14 secondary care providers and 10 clinical commissioning groups (CCGs), listed in Supplementary Material.

The FIT diagnostic service (comprising of FIT kits for patients, patient instructions, lab processing of FIT and timely associated reporting of results) was available to GPs to triage patients with low-risk symptoms of CRC, as defined by NG12 and DG30. ${ }^{10,11}$ Patients meeting the following criteria were eligible for a FIT (these criteria were derived from the 2015 NG12 for faecal occult blood testing, current at the time of project design):

- Aged 50 years and over with unexplained abdominal pain or weight loss

- Aged 50-60 years with change in bowel habit or irondeficiency anaemia

- Aged 60 years and over with anaemia, even in the absence of iron deficiency

The laboratory service was provided by Severn Pathology in Bristol and the Exeter Clinical Laboratory in Exeter using the HMJACKarc analyser. This assay has a recommended analytical range of $7-400 \mu \mathrm{g} \mathrm{Hb} / \mathrm{g}$ faeces (though some values below $7 \mu \mathrm{g} \mathrm{Hb} / \mathrm{g}$ faeces were reported); results over $400 \mu \mathrm{g} \mathrm{Hb} / \mathrm{g}$ faeces were recorded as $>400 \mu \mathrm{g} \mathrm{Hb} / \mathrm{g}$ faeces. A threshold value of $\geq 10 \mu \mathrm{g} \mathrm{Hb} / \mathrm{g}$ faeces defined a 'positive' test, as per DG30. ${ }^{11}$ Test kit packs were delivered to primary care practices including: the test unit, instructions for use, a form to select the indication for the test, and a prepaid envelope for the patient to return the completed test to the laboratory. Test results were returned to practices electronically in Devon, Cornwall and Avon. In Somerset, Wiltshire and Gloucestershire, reports were initially sent by post, and later electronically.

Information about the service was publicised through local CCG newsletters and through the local Cancer Research UK Facilitator Team, who provided practice-level training and support. GPs were provided with written, online, and video support for using the FIT service, indications for the test and how to use it, and advice on how to deal with a positive test. GPs were advised in the guidance that if faecal haemoglobin concentration (f- $\mathrm{Hb}$ ) was $\geq 10 \mu \mathrm{g} \mathrm{Hb} / \mathrm{g}$ faeces they should consider using an urgent referral for suspected cancer under the local secondary care provider's arrangements. They were also advised that occult blood in the faeces can be caused by a wide variety of benign conditions as well as CRC, and further assessment may be appropriate to rule these out before referring.

\section{Data collection}

All patients with a FIT analysed from 1 June 2018 to 31 December 2018 were included in this study. Data extracted from the two laboratories included the test date, result, indication, patient year of birth and gender. Separately, each of the 14 secondary care providers in the region extracted data, including stage at diagnosis, on any cancer identified from 1 June 2018 to 31 December 2019 after entry into upper or lower gastrointestinal services. This captured cancers diagnosed by all routes, including screening and incidental findings such as routine referral or emergency admission. This allowed for 12 months of follow-up time for all patients, during which missed CRC diagnoses in FIT negative patients were likely (but not certain) to be diagnosed through other routes. Had a longer period of follow-up been chosen, some of the CRCs diagnosed in FIT negative patients after 12 months may not have been causing symptoms at the time of testing. Only cancers identifiable on a gastrointestinal (Gl) pathway were identified: non-Gl cancers, referred to other cancer diagnostic pathways, were not identified.

Test results were matched against referral and diagnosis data by each of the secondary care providers using NHS number, then removed and replaced with a randomly allocated study number. Year of birth was used as a secondary confirmation of correct matching of patient records. This was done to adhere with information governance requirements and to ensure completeness of the full patient pathway. GPs were advised not to offer multiple FITs to individual patients; where more than one test was recorded for one patient, the earliest result was used.

\section{Statistical analysis and power calculation}

Summary statistics were used to describe the cohort, and to estimate the performance of FIT in this population, including sensitivity, specificity, positive predictive value (PPV), and negative predictive value. A Chi-squared test was used to compare the proportion of male participants, and a Mann-Whitney test to compare the median age, between those with a result at/above and below the threshold. A receiver-operating characteristic curve was produced for quantitative $\mathrm{f}-\mathrm{Hb}$ against CRC diagnosis. Logistic regression was used to model the relationship between cancer and $\mathrm{f}-\mathrm{Hb}$ (treated as a continuous variable), after logtransformation to improve the final model fit. Non-linearity in the relationship between $\mathrm{f}-\mathrm{Hb}$ and $\mathrm{CRC}$ was explored using fractional polynomials, though goodness of fit was not improved by doing so. Consequently, a linear term was retained. The probability of being diagnosed with CRC in the next year for a given $\mathrm{f}-\mathrm{Hb}$ value was estimated from the final model, in particular identifying the value equating to an individual cancer risk of 3\%, to mirror NICE recommendations for urgent investigation. ${ }^{10}$ Stata version 16 was used for all analyses. ${ }^{15}$ Diagnostic test summary statistics were estimated with the DIAGT module. ${ }^{16}$

A simulation approach was used to estimate the sample size required to achieve $95 \%$ confidence intervals of $2.2 \%$ to $4.0 \%$ around a cancer risk of $3 \%$ from the logistic regression. Assuming a linear relationship between $\mathrm{f}-\mathrm{Hb}$ and $\mathrm{CRC}$ risk suggested a sample of 2250 would be sufficient so long as the threshold was within the central core of the distribution of $\mathrm{f}-\mathrm{Hb}$ levels. It was estimated that 10,000 tests would be used in a year; data were collected over seven months to meet the sample size requirement. In practice it was comfortably exceeded, increasing precision.

\section{Data governance}

As this project was evaluating service delivery, and not changing routine clinical practice, ethical approval was not required. Data sharing agreements were drawn up between all parties, and Caldicott guardian approvals were in place to allow data sharing. The requirement for individual NHS numbers for use within this evaluation meets the criteria set out in section 6 of the General Data Protection Regulation: Guidance on Lawful Processing. The 
processing of data is based upon GDPR Article 6(1)(e)_'exercise of official authority' and article 9(2)(h) 'management of health and care services'. The enabling legislation is the NHS Act 2006 section $13 \mathrm{E}$, including the duty on NHS England to 'secure continuous improvement in the quality of services'. The same basis supported the secondary care providers supplying data. The study protocol is available on the University of Exeter website at http://hdl.handle. net/10871/122303. This manuscript was deposited as a preprint on medrXiv. ${ }^{17}$

\section{RESULTS}

From 1 June 2018 to 31 December 2018, 3890 samples were submitted to and analysed by the two laboratories. The median age of tested patients was 65 years (interquartile range (IQR): 56-75) and 1644 (42.6\%) were male. Criteria for investigation were: $1617(41.6 \%)$ aged $\geq 50$ years with abdominal pain or weight loss; $1194(30.7 \%)$ aged $<60$ years with changes in bowel habit or iron-deficiency anaemia; 930 (23.9\%) aged $>60$ years and with anaemia (in absence of iron deficiency). No criteria for investigation were recorded in 149 (3.8\%).

FIT results

A $\mathrm{f}-\mathrm{Hb} \geq 10 \mu \mathrm{g} \mathrm{Hb} / \mathrm{g}$ faeces (test positive) was recorded for 618 patients $(15.9 \%)$. Patients above the $\mathrm{f}-\mathrm{Hb}$ threshold were more often male ( $46.1 \%$ males vs $42.0 \%$ females, $p=0.017)$ and older (median age 71 vs 63, IQR 60 to 79, $p<0.001$ ). Of patients above the $\mathrm{f}-\mathrm{Hb}$ threshold, the median age was 71.7 years (IQR 60.1-79.7); $288(46.3 \%)$ were male. The median result was $36 \mu \mathrm{g} \mathrm{Hb} / \mathrm{g}$ faeces (IQR 17-149). Figure 1 shows the distribution of $\mathrm{f}-\mathrm{Hb}$ in patients above the threshold.

Referrals in patients with a FIT

Of 618 patients with $\mathrm{f}-\mathrm{Hb} \geq 10 \mu \mathrm{g} \mathrm{Hb} / \mathrm{g}$ faeces, 458 (74.1\%) were referred to lower gastrointestinal $(\mathrm{Gl})$ services within three months (Fig. 2). Of the remaining 160, 36 were referred up to 12 months after FIT. Cancer outcomes for these patients are shown in Fig. 2. Of 3272 patients with $\mathrm{f}-\mathrm{Hb}<10 \mu \mathrm{g} \mathrm{Hb} / \mathrm{g}$ faeces, 324 (9.9\%) were referred to lower $\mathrm{Gl}$ services within three months.

Cancer outcomes

Table 1 shows the cancers identified during the year after FIT. The positive predictive value of FIT in this low-risk symptomatic population is $7.0 \%(95 \% \mathrm{Cl} 5.1-9.3 \%)$, and the negative predictive

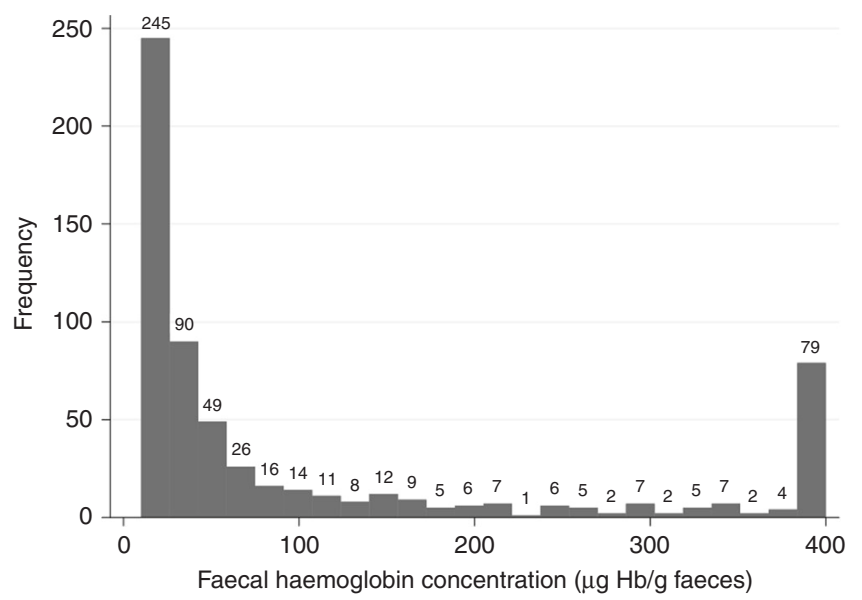

Fig. 1 Histogram of quantitative faecal immunochemical test results. This histogram presents the quantitative faecal immunochemical test results for patients with a $\mathrm{f}-\mathrm{Hb}$ over the threshold of $10 \mu \mathrm{g} \mathrm{Hb} / \mathrm{g}$ faeces (618 primary care patients), with low-risk symptoms of possible colorectal cancer. value is $99.8 \%$ (Cl $99.5-99.9 \%)$. The sensitivity in this population is $84.3 \%(\mathrm{Cl} 71.4-93.0 \%)$, and the specificity $85.0 \%(83.8-86.1 \%)$. The area under the ROC curve is $0.92(\mathrm{Cl} \mathrm{0.86-0.96)}$ (Fig. 3).

The median number of days from FIT to diagnosis of CRC in patients testing above the $\mathrm{f}-\mathrm{Hb}$ threshold was 34 (IQR 23-56). Staging data were available for 31 of 43 patients: 6 Dukes' $A ; 5$ Duke's B; 12 Dukes' C; 8 Dukes' D. The median number of days to diagnosis in patients with a result below the $\mathrm{f}-\mathrm{Hb}$ threshold was 57 days (IQR 37-197). Staging data were available for six of eight patients: 1 Duke's B; 2 Dukes' C; 3 Dukes' D.

Cancer risk by $\mathrm{f}-\mathrm{Hb}$

Figure 4 shows the estimated probability that an individual will be diagnosed with $\mathrm{CRC}$ for a given $\mathrm{f}-\mathrm{Hb}$ level, estimated from the logistic regression model. Using this model, a $\mathrm{f}-\mathrm{Hb}$ level of $37 \mu \mathrm{g}$ $\mathrm{Hb} / \mathrm{g}$ faeces $(\mathrm{Cl} 26-50)$ in an individual with that result corresponds to a CRC risk of $3 \%$. Five patients with CRC had a $f-$ $\mathrm{Hb}$ value in the range $5-9 \mu \mathrm{g} \mathrm{Hb} / \mathrm{g}$ faeces.

\section{DISCUSSION}

This study reports the use of FIT for detection of CRC in a primary care symptomatic population. The test performed very well using the threshold value of $\geq 10 \mu \mathrm{g} \mathrm{Hb} / \mathrm{g}$ faeces. Test sensitivity and specificity were $84.3 \%$ and $85.0 \%$, respectively, both notably high figures for a primary care cancer test. Using this threshold, the positive predictive value of $\mathrm{f}-\mathrm{Hb} \geq 10 \mu \mathrm{g} \mathrm{Hb} / \mathrm{g}$ faeces was $7.0 \%$, and the negative predictive value $99.8 \%$, in a population with an overall prevalence of CRC of $1.3 \%$. FIT also performed well irrespective of gender or age. A f-Hb level of $37 \mu \mathrm{g} \mathrm{Hb} / \mathrm{g}$ faeces corresponded to an individual's CRC risk of $3 \%$.

Strengths and limitations

The strengths of this study are its size, and its setting being where the test will be used, eliminating spectrum bias. The three symptom groupings used by GPs to prompt FIT were estimated to have PPVs in primary care in the range $1-3 \%$, and the overall prevalence of $1.3 \%$ fell within that range. These defined symptoms match the current (September 2020) NICE guidance on when to offer faecal testing for colorectal cancer to adults without rectal bleeding. ${ }^{10}$ Every one of the 14 secondary care providers in the region were recruited, increasing reliability and generalisability. Cancer metrics in the NHS are very accurately maintained; dedicated cancer managers ensure accurate data recording, and secondary care provider performance on cancer metrics is regularly published in the public domain. Furthermore, all secondary care providers of cancer services within England are required to use nationally defined datasets eliminating disparity in data definitions. Despite the thorough methods, it is possible that a small number of cancers were missed, although this is unlikely to affect the overall interpretation of the results. Crucially, the methods allowed the identification of CRCs in those not offered further investigation after the FIT result was received, and a long follow-up period of 1 year was achieved.

The age group studied, with a median age of 65 years for those tested, is close to the median age for CRC diagnosis of 72 years, suggesting the GPs were using the test in those genuinely considered to have a real-but small-risk of cancer. More women were tested, whereas CRC is slightly more common in men. This may reflect the entry criteria, particularly with two of the three criteria incorporating iron-deficiency anaemia, a condition more common in women, ${ }^{18}$ or the fact that women are more likely to seek medical intervention. ${ }^{19}$ Symptom data could not be verified, but the overall prevalence figure suggests testing was rarely extended into higher-risk groups. Completing the test was patient driven; only tests which were completed and returned to the lab were reported; it is not known how many tests were handed out by GPs and not returned to the labs. Both 


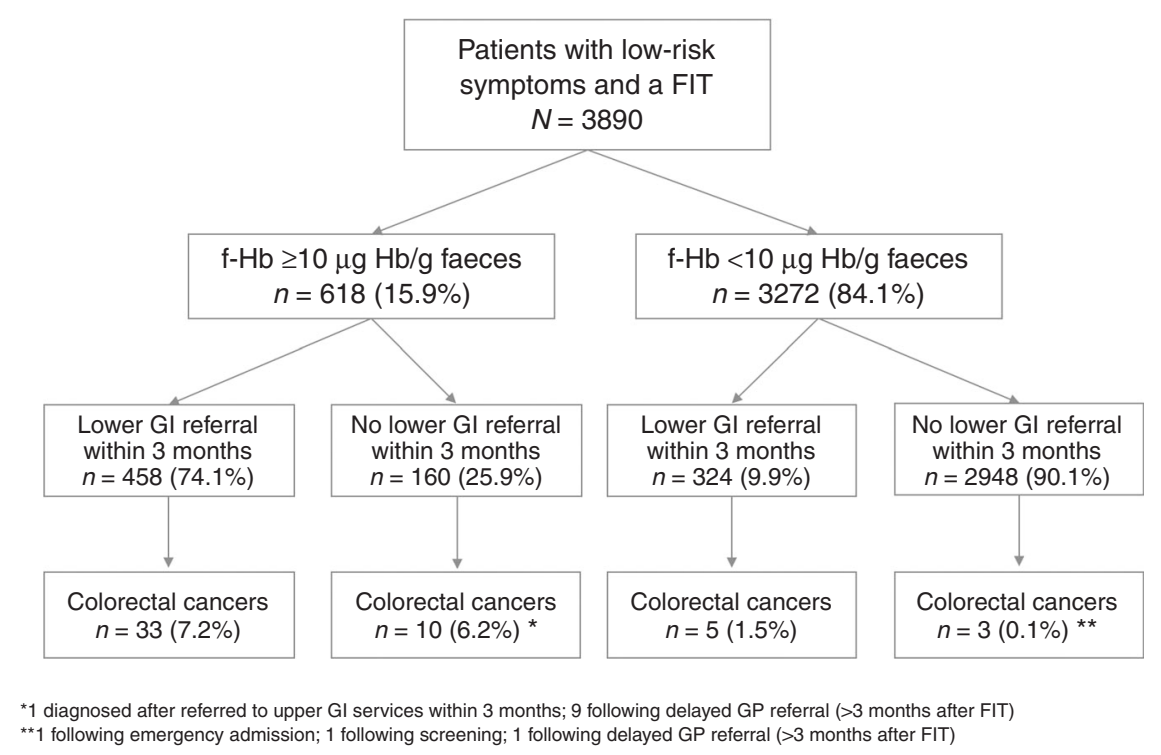

Fig. 2 Flow diagram of referrals and diagnoses in patients with a FIT. This flow diagram shows the number of patients tested, split by test result (over/at or under the threshold), and subsequent lower gastrointestinal referrals and colorectal cancers diagnosed.

Table 1. The number of colorectal, oesophago-gastric and pancreatic cancers diagnosed in total, for patients with $\mathrm{f}-\mathrm{Hb}$ at/above and below the $10 \mu \mathrm{g} \mathrm{Hb} / \mathrm{g}$ faeces threshold, within 12 months of FIT date.

\begin{tabular}{lrrr}
\hline Cancer & Total & $\begin{array}{l}\geq 10 \mu \mathrm{g} \mathrm{Hb} / \mathrm{g} \text { faeces } \\
n=618\end{array}$ & $\begin{array}{l}<10 \mu \mathrm{g} \mathrm{Hb} / \mathrm{g} \text { faeces } \\
n=3272\end{array}$ \\
\hline Colorectal & 51 & $43(7.0 \%)$ & $8(0.2 \%)$ \\
Oesophago-gastric & 9 & $3(0.5 \%)$ & $6(0.2 \%)$ \\
Pancreatic & 7 & $1(0.2 \%)$ & $6(0.2 \%)$ \\
Total & 67 & $47(7.6 \%)$ & $20(0.6 \%)$ \\
\hline
\end{tabular}

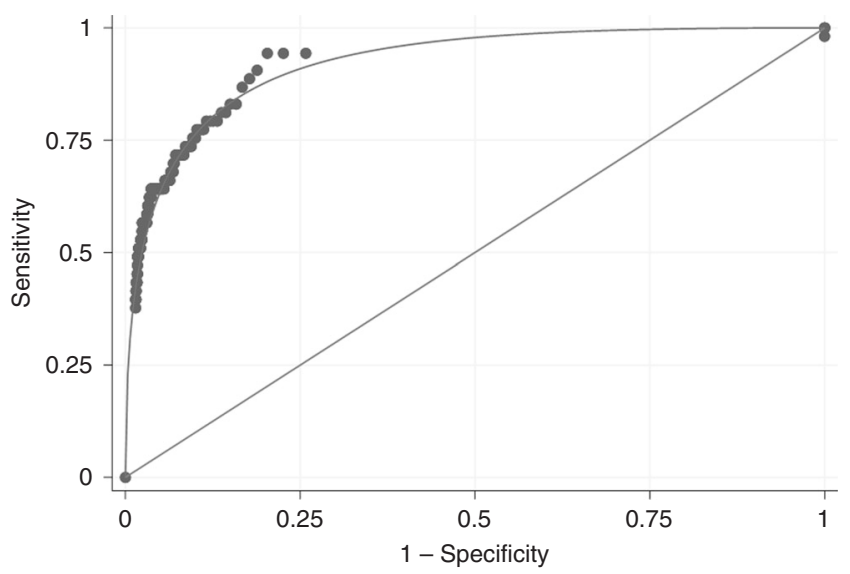

Fig. 3 Receiver operator characteristic (ROC) curve for the faecal immunochemical test in the low-risk symptomatic primary care population. Area under the curve $=0.92(\mathrm{Cl} 0.86-0.96)$.

participating laboratories used the same FIT system; achieving consistency across the cohort, but meaning the results are not applicable to other systems. ${ }^{20}$

Comparison with previous literature

Three recent studies can be compared, as they examined FIT in the symptomatic primary care population, rather than the

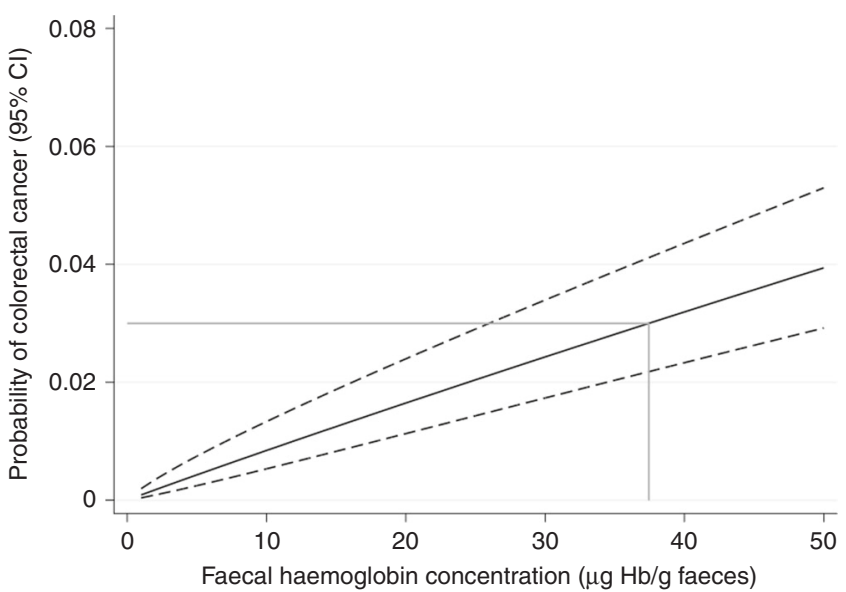

Fig. 4 Predicted probability of colorectal cancer against $\mathrm{f}-\mathrm{Hb}$, with $\mathbf{9 5 \%}$ confidence limits. The orange line shows the $\mathrm{f}-\mathrm{Hb}$ level that corresponds to a colorectal cancer risk of $3 \%$ in an individual with that result.

screening or referred populations: two of these also used a threshold of $10 \mu \mathrm{g} \mathrm{Hb} / \mathrm{g}$ faeces. Juul et al. studied 3462 Danish primary care patients aged $\geq 30$ years, with symptoms not meriting urgent colonoscopy, but not defined further. ${ }^{21}$ In that study, FIT was also recommended in patients diagnosed with irritable bowel syndrome, lest this were a misdiagnosis. $15.6 \%$ patients tested over the threshold, and $9.4 \%$ of these $(\mathrm{Cl} 7.0-11.9 \%)$ had a CRC diagnosed in the next 3 months. There were fewer than three cancers identified in those below the threshold (the inexact number reflecting Danish data protection rules). Nicholson et al. followed up 9896 primary care patients in Oxfordshire, England, for 6 months after FITs were ordered in primary care. The entry criteria did not match NICE guidance DG30 or NG12, and included rectal bleeding. The sensitivity for CRC was $90.5 \%$ (Cl 84.9-96.1\%), and the positive predictive value of a positive test $10.1 \%(\mathrm{Cl}$ 8.2-12.0\%).2 Chapman et al. stratified patients presenting in primary care with any lower Gl symptoms (except rectal bleeding or a rectal mass) by $\mathrm{f}-\mathrm{Hb}$ level, and anaemia in one strata. ${ }^{23} \mathrm{PPVs}$ were: $30.0 \%$ in the $\geq 150.0 \mu \mathrm{g} \mathrm{Hb} / \mathrm{g}$ faeces group; $4.4 \%$ in the $10.0-149.9 \mu \mathrm{g} \mathrm{Hb} / \mathrm{g}$ faeces group; 0 in the $4.0-9.9 \mu \mathrm{g} \mathrm{Hb} / \mathrm{g}$ faeces 
with anaemia group, $2.9 \%$ in the $4.0-9.9 \mu \mathrm{g} \mathrm{Hb} / \mathrm{g}$ faeces without anaemia group and $0.2 \%$ in the $<4.0 \mu \mathrm{g} \mathrm{Hb} / \mathrm{g}$ faeces group. The PPV of $7 \%$ for results over the $10 \mu \mathrm{g} \mathrm{Hb} / \mathrm{g}$ faeces threshold in the present study is the lowest of the three that used that threshold, which may reflect the stricter criteria for use, in particular excluding patients with rectal bleeding, but matching current national guidance. ${ }^{10}$ The PPV in patients with $\mathrm{f}-\mathrm{Hb}$ from $4.0-9.9 \mu \mathrm{g}$ $\mathrm{Hb} / \mathrm{g}$ faeces in our cohort was $1.7 \%$; comparable to Chapman et al.'s results. ${ }^{23}$ As a comparison, the sensitivity of $84.3 \%$ reported here is higher than in the screening population of $67.0 \%(\mathrm{Cl}$ $59.0-74.0 \%$, with thresholds of $\left.>50 \mu \mathrm{g} / \mathrm{g}^{24}\right)$, and lower than that in referred populations of $93.3 \%(\mathrm{Cl} 80.7-98.3 \%$, thresholds of $>10$ $\mu \mathrm{g} / \mathrm{g})^{25}$

Clinical and research use of the results

The values reported in this study are excellent for a cancer triage test in primary care. The performance of diagnostic tests is generally worse as the prevalence of the target condition falls. ${ }^{14}$ In primary care, gastrointestinal complaints are common, and the symptoms of CRC overlap both with less common cancers, such as pancreatic or oesophago-gastric, and with common benign conditions. With most symptoms (apart from rectal bleeding) the likelihood of CRC is low, often in the range $1-3 \% .{ }^{26} \mathrm{~A}$ large UK primary care study showed that patients would opt for cancer investigation even for risks as low as $1 \% .{ }^{27}$ FIT has been introduced to allow primary care investigation of such patients. It works in classical Bayesian fashion: from a prior risk of CRC of $1.3 \%$ in the symptomatic population, a result over the $10 \mu \mathrm{g} \mathrm{Hb} / \mathrm{g}$ faeces threshold increased the risk to $7.0 \%$, and a result below the threshold reduced it to $0.2 \%$, which is approximately the whole population background risk, including those without symptoms. ${ }^{26}$ Furthermore, in five of the eight cancers with a result under the threshold, the patient's GP still requested urgent investigation for possible CRC, probably because continuing symptoms allowed the GP to 'overrule' the negative test. Conversely, nearly a quarter of patients who tested over the threshold were not offered investigation within three months, although ultimately all who had CRC were investigated within a year. CRC incidence was similar in those who were referred within three months and those who were referred later; delays in the referral process should be avoided.

Other cancers were diagnosed in participants in this study. Sixteen oesophago-gastric or pancreatic cancers were found, only four having a FIT result over the threshold. This suggests that GPs should consider other intra-abdominal cancers in patients with $\mathrm{f}-\mathrm{Hb}<10 \mu \mathrm{g} \mathrm{Hb} / \mathrm{g}$ faeces and continuing symptoms, even though FIT is intended for the detection of colorectal cancers as $\mathrm{Hb}$ is immunologically degraded in the small intestine.

While the PPV at or above the current threshold of $10 \mu \mathrm{g} \mathrm{Hb} / \mathrm{g}$ faeces is $7 \%$, the risk of having CRC for an individual with $\mathrm{f}-\mathrm{Hb}$ of exactly this value is $1 \%$ or lower (Fig. 4). Given this risk is lower than the $3 \%$ chosen to underpin the NICE NG12 recommendations for urgent cancer investigation, ${ }^{10}$ there may be scope to raise the threshold at which urgent definitive investigations are undertaken. $\mathrm{f}-\mathrm{Hb}$ of $37 \mu \mathrm{g} \mathrm{Hb} / \mathrm{g}$ faeces (Cl 26-50) would identify those with a personal $3 \%$ risk of cancer, though the large uncertainty on this estimate may warrant the use of a lower value until more data are available to reduce this uncertainty. Such a change may be appropriate while endoscopy resources are severely curtailed by COVID-19 precautions, with 'safety netting' by GP review for those with $\mathrm{f}-\mathrm{Hb}$ levels between 10 and $36 \mu \mathrm{g} \mathrm{Hb} / \mathrm{g}$ faeces. ${ }^{28}$ In the long term, however, the UK's aspiration is for improvements in cancer diagnosis to increase the proportion of cancer patients diagnosed at stage I or II to $75 \%$ by 2028 (from a pre-COVID $~ 53 \%$ ). ${ }^{29}$ If CRC improvements are to contribute to this target, it may be that the threshold should be retained at $10 \mu \mathrm{g} \mathrm{Hb} / \mathrm{g}$ faeces, or even lowered further, though not below the level where the test is considered reliable, currently $7 \mu \mathrm{g} \mathrm{Hb} / \mathrm{g}$ faeces.
Several research needs arise from this study. The first is a healtheconomic analysis, examining the choice of $\mathrm{f}-\mathrm{Hb}$ threshold from that perspective. Second, it may be possible to combine data on symptoms, other lab tests, and demographics with $\mathrm{f}-\mathrm{Hb}$ to increase the predictive power of FIT. A third strand of research-not directly related to this study, but overlapping-considers whether FIT can be used to triage the high-risk population. Such studies are underway; in Scotland, patients reporting rectal bleeding (considered a 'red flag' symptom) in primary care with a $\mathrm{f}-\mathrm{Hb}<10 \mu \mathrm{g} \mathrm{Hb} / \mathrm{g}$ faeces were unlikely to be harbouring CRC or other serious bowel disease; similar results were observed in Sweden. ${ }^{31}$ Those will complement the study reported here, and establish the final place for FIT in colorectal cancer triage.

\section{CONCLUSION}

FIT in the low-risk primary care population performs well. Falsenegatives are few in number, and many of those with a falsenegative test appear to receive timely investigation despite $\mathrm{f}-\mathrm{Hb}$ below the $10 \mu \mathrm{g} \mathrm{Hb} / \mathrm{g}$ faeces threshold. The false-positive rate is $93 \%$, meaning 13 patients with $\mathrm{f}-\mathrm{Hb}$ over $10 \mu \mathrm{g} \mathrm{Hb} / \mathrm{g}$ faeces have to undergo colonoscopy to identify one CRC. This is a major diagnostic advance; low-risk patients were previously either not investigated, and had more emergency admissions and worst survival, ${ }^{8,9}$ or were referred for colonoscopy. The background rate of cancer of $1.3 \%$ in this population meant 77 patients had to be offered colonoscopy to identify one cancer, potentially swamping endoscopy services, and putting patients at a small risk of complications. Clinically, therefore, FIT works, although health-economic aspects are as yet uncertain.

\section{ACKNOWLEDGEMENTS}

With thanks to Allen Barker, all cancer managers at contributing secondary care providers, and the patients whose data contributed to this evaluation. This manuscript was deposited as a preprint on medrXiv. ${ }^{17}$

\section{AUTHOR CONTRIBUTIONS}

All authors were involved in the design and inception of the study. S.B., P.T., T.M.C.D., A.A., S.J.D., C.N., S.W., R.B., J.M. and J.R. contributed to data collection and data governance. S.B., G.A. and W.H. carried out data analysis and created the first draft of the manuscript along with F.W. All authors reviewed and contributed to the final draft of the manuscript. S.B. is responsible for the overall content as guarantor. The corresponding author attests that all listed authors meet authorship criteria and that no others meeting the criteria have been omitted.

\section{ADDITIONAL INFORMATION}

Ethics approval and consent to participate Caldicott guardians in each participating secondary care provider approved the use of data for this evaluation. As this project was not changing routine clinical practice, but evaluating existing provision, ethical approval was not required. Data sharing agreements were drawn up between all parties, and Caldicott guardian approvals were in place to allow data sharing. The requirement for individual NHS numbers for use within this evaluation meets the criteria set out in section 6 of the General Data Protection Regulation: Guidance on Lawful Processing. The processing of data is based upon GDPR Article 6 (1)(e)-'exercise of official authority' and article 9(2)(h) 'management of health and care services'. The enabling legislation is the NHS Act 2006 section 13E, including the duty on NHS England to 'secure continuous improvement in the quality of services'. The same basis supported the secondary care providers supplying data.

Data availability As the raw data analysed in this study include patient identifiable information, we cannot share them currently. We are happy to discuss requests for data with the Caldicott guardian (J.R.)

Competing interests The authors declare no competing interests.

Funding information This research arises from the CanTest Collaborative, which is funded by Cancer Research UK [C8640/A23385], of which W.H. and F.M.W. are Directors, G.A.A. is Co-investigator and S.B. is Senior Postdoctoral Researcher. It was 
also supported by the Peninsula Cancer Alliance, the Somerset, Wiltshire, Avon, and Gloucestershire (SWAG) Cancer Alliance, and NHS England.

Supplementary information is available for this paper at https://doi.org/10.1038/ s41416-020-01221-9.

Publisher's note Springer Nature remains neutral with regard to jurisdictional claims in published maps and institutional affiliations.

\section{REFERENCES}

1. Dekker, E., Tanis, P. J., Vleugels, J. L. A., Kasi, P. M. \& Wallace, M. B. Colorectal cancer. Lancet 394, 1467-1480 (2019).

2. Jodal, H. C., Helsingen, L. M., Anderson, J. C., Lytvyn, L., Vandvik, P. O. \& Emilsson, L. Colorectal cancer screening with faecal testing, sigmoidoscopy or colonoscopy: a systematic review and network meta-analysis. BMJ Open 9, e032773 (2019).

3. Elliss-Brookes, L., McPhail, S., Ives, A., Greenslade, M., Shelton, J., Hiom, S. et al. Routes to diagnosis for cancer-determining the patient journey using multiple routine data sets. Br. J. Cancer 107, 1220-1226 (2012).

4. van Melle, M., Yep Manzano, S. I., Wilson, H., Hamilton, W., Walter, F. M. \& Bailey, S. E. Faecal immunochemical test to triage patients with abdominal symptoms for suspected colorectal cancer in primary care: review of international use and guidelines. Fam. Pract. 7, cmaa043 (2020).

5. Health Services Management Centre. Scoping the Future (Health Services Management Centre, 2015). https://www.cancerresearchuk.org/sites/default/files/ scoping_the_future_-_final.pdf.

6. Hamilton, W., Walter, F. M., Rubin, G. \& Neal, R. D. Improving early diagnosis of symptomatic cancer. Nat. Rev. Clin. Oncol. 13, 740-749 (2016).

7. NICE. Referral Guidelines for Suspected Cancer (NICE, London, 2005).

8. Cleary, J., Peters, T. J., Sharp, D. \& Hamilton, W. Clinical features of colorectal cancer before emergency presentation: a population-based case-Control study. Fam. Pract. 24, 3-6 (2007).

9. Stapley, S., Peters, T. J., Sharp, D. \& Hamilton, W. The mortality of colorectal cancer in relation to the initial symptom at presentation to primary care and to the duration of symptoms: a cohort study using medical records. $\mathrm{Br}$. J. Cancer [Internet] 95, 1321-1325, http://www.ncbi.nlm.nih.gov/pubmed/17060933 (2006).

10. NICE. Suspected cancer: recognition and referral [NG12] [Internet]. http://www.nice. org.uk/guidance/NG12 (2015).

11. NICE. Quantitative faecal immunochemical tests to guide referral for colorectal cancer in primary care [DG30] [Internet]. https://www.nice.org.uk/guidance/dg30/ chapter/1-Recommendations (2017).

12. Westwood, M., Ramos, I. C., Lang, S., Luyendijk, M., Zaim, R., Stirk, L. et al. Faecal immunochemical tests to triage patients with lower abdominal symptoms for suspected colorectal cancer referrals in primary care: a systematic review and cost-effectiveness analysis. Health Technol. Assess. (Rockv.) 21, 1-234 (2017).

13. Mowat, C., Digby, J., Strachan, J. A., Wilson, R., Carey, F. A., Fraser, C. G. et al. Faecal haemoglobin and faecal calprotectin as indicators of bowel disease in patients presenting to primary care with bowel symptoms. Gut 65, 1463-1469 (2016).

14. Usher-Smith, J. A., Sharp, S. J. \& Griffin, S. J. The spectrum effect in tests for risk prediction, screening, and diagnosis. BMJ 353, i3139 (2016)

15. StataCorp. Stata Statistical Software: Release 14. (2015).

16. Seed, P. \& Tobias, A. DIAGT: Stata module to report summary statistics for diagnostic tests compared to true disease status. Stat. Softw. Comp. https://ideas. repec.org/c/boc/bocode/s423401.html (2010).

17. Bailey, S. E. R., Abel, G. A., Atkins, A., Byford, R., Davies, S.-J., Mays, J. et al. Diagnostic performance of the faecal immunochemical test for patients with low-risk symptoms of colorectal cancer in primary care: a service evaluation in the South West of England. medRxiv [Internet]. http://medrxiv.org/content/early/2020/08/ 23/2020.08.21.20173534.abstract (2020).
18. Lopez, A., Cacoub, P., Macdougall, I. C. \& Peyrin-Biroulet, L. Iron deficiency anaemia. Lancet 387, 907-916 (2016).

19. Wang, Y., Hunt, K., Nazareth, I., Freemantle, N. \& Petersen, I. Do men consult less than women? An analysis of routinely collected UK general practice data. BMJ Open 3, e003320 (2013).

20. Piggott, C., Carroll, M. R. R., John, C., O'Driscoll, S. \& Benton, S. C. Analytical evaluation of four faecal immunochemistry tests for haemoglobin. Clin. Chem. Lab Med. https://doi.org/10.1515/cclm-2020-0251 (2020). published online ahead of print.

21. Juul, J. S., Hornung, N., Andersen, B., Laurberg, S., Olesen, F. \& Vedsted, P. The value of using the faecal immunochemical test in general practice on patients presenting with non-alarm symptoms of colorectal cancer. Br. J. Cancer [Internet] 119, 471-479 (2018).

22. Nicholson, B. D., James, T., Paddon, M., Justice, S., Oke, J. L., East, J. E. et al. Faecal immunochemical testing for adults with symptoms of colorectal cancer attending English primary care: a retrospective cohort study of 14487 consecutive test requests. Aliment Pharmacol. Ther. 52, 1-11 (2020).

23. Chapman, C., Thomas, C., Morling, J., Tangri, A., Oliver, S., Simpson, J. A. et al. Early clinical outcomes of a rapid colorectal cancer diagnosis pathway using faecal immunochemical testing in Nottingham. Color Dis. 22, 679-688 (2020).

24. Lee, J. K., Liles, E. G., Bent, S., Levin, T. R. \& Corley, D. A. Accuracy of fecal immunochemical tests for colorectal cancer: systematic review and metaanalysis. Ann. Intern Med. 160, 171 (2014).

25. Quyn, A. J., Steele, R. J. C., Digby, J., Strachan, J. A., Mowat, C., McDonald, P. J. et al. Application of NICE guideline NG12 to the initial assessment of patients with lower gastrointestinal symptoms: not FIT for purpose? Ann. Clin. Biochem. 55, 69-76 (2018).

26. Hamilton, W., Round, A., Sharp, D. \& Peters, T. Clinical features of colorectal cancer before diagnosis: a population-based case-control study. Br. J. Cancer 93, 399-405 (2005).

27. Banks, J., Hollinghurst, S., Bigwood, L., Peters, T. J., Walter, F. M. \& Hamilton, W. Preferences for cancer investigation: a vignette-based study of primary-care attendees. Lancet Oncol. 15, 232-240 (2014).

28. Rees, C. J., East, J. E., Oppong, K., Veitch, A., McAlindon, M., Anderson, J. et al. Restarting gastrointestinal endoscopy in the deceleration and early recovery phases of COVID-19 pandemic: guidance from the British Society of Gastroenterology. Clin. Med. 20, 352-358 (2020).

29. Alderwick, H. \& Dixon, J. The NHS long term plan. BMJ 364, I84 (2019).

30. Digby, J., Strachan, J. A., McCann, R., Steele, R. J. C., Fraser, C. G. \& Mowat, C. Measurement of faecal haemoglobin with a faecal immunochemical test can assist in defining which patients attending primary care with rectal bleeding require urgent referral. Ann. Clin. Biochem. 57, 325-327 (2020).

31. Högberg, C., Gunnarsson, U., Cronberg, O., Thulesius, H., Lilja, M. \& Jansson, S. Qualitative faecal immunochemical tests (FITs) for diagnosing colorectal cancer in patients with histories of rectal bleeding in primary care: a cohort study. Int. J. Colorectal Dis. 35, 2035-2040 (2020).

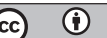

Open Access This article is licensed under a Creative Commons Attribution 4.0 International License, which permits use, sharing, adaptation, distribution and reproduction in any medium or format, as long as you give appropriate credit to the original author(s) and the source, provide a link to the Creative Commons license, and indicate if changes were made. The images or other third party material in this article are included in the article's Creative Commons license, unless indicated otherwise in a credit line to the material. If material is not included in the article's Creative Commons license and your intended use is not permitted by statutory regulation or exceeds the permitted use, you will need to obtain permission directly from the copyright holder. To view a copy of this license, visit http://creativecommons. org/licenses/by/4.0/.

(c) The Author(s) 2021 